\title{
The Relationship between Emotional Intelligence \& Injury in Wrestlers
}

\author{
Jamal Fazel Kalkhoran (Corresponding author) \\ Associate Professor, Department of Physical Education and Sport Sciences, University of Tehran, IRAN \\ kargar shomali15university of Tehran, Tehran,Iran \\ Tel: 00989122863848 E-mail: jfazzel@ut.ac.ir \\ Benyamin Ghelichpoor Dashlibroon \\ Master of Science of Motor Behavior, University of Tehran, IRAN \\ Kargar Shomali15 University of Tehran, Tehran, Iran \\ Tel: 00989112764244 E-mail: xinzhou.song@pku.edu.cn \\ Amir Shariati \\ Master of Science of Motor Behavior, University of Tehran, IRAN \\ Kargar Shomali15 University of Tehran, Tehran, Iran \\ Tel: 00989125522178 E-mail: amir.shariati@ut.ac.ir
}

Received: 11-05- 2013

doi:10.7575/aiac.ijkss.v.1n.2p.19
Accepted: 20-07- 2013

Published: 30-07- 2013

\begin{abstract}
In this study, emotional intelligence, which is the ability to understand the excitement and emotion, was evaluated in Iranian elite wrestlers (with the mean age 19.40 5.5years) to determine its relationship with sports injuries. For this purpose, 90 wrestlers, who had participated in Country Championships and who had been invited to Iranian national team in 2012, participated in this research. For data collection, profile sheets, the Schulte Self Report Emotional Intelligence Test, sports injury reports and interviews with athletes and team physicians in addition to available medical records were used. Based on the wrestlers' injury reports, there was an average of 12 injuries in 2012. The results showed significant negative relationships between the ability of wrestlers to regulate emotions $(\mathrm{p}=-0.309)$, their ability to use emotions $(\mathrm{p}=-0.313)$, their ability to assess their emotions $(\mathrm{p}=-0.582)$, their ability to generally regulate their emotions ( $\mathrm{p}=-\mathrm{0.445)}$ with the number of sports injuries. Also, only the ability to assess the emotions could predict the probability of injuries in wrestlers, that is, the wrestlers who had high ability to regulate their emotions suffered from lower injuries. The significant relationship between the components of emotional intelligence and the number of sports injuries showed that the athletes who had lower ability to regulate their emotional intelligence might put themselves more in risky situations and consequently more injuries. Coaches and officials are recommended to identify these athletes and to improve their emotional intelligence to reduce the probability of their sports injuries
\end{abstract}

Keywords: Emotional intelligence, sports injury, elite wrestlers

\section{Introduction}

Sport injury is a problem most athletes face in their sport lifetime and is a concern for athletes and coaches. Therefore, it is necessary to be aware, prevent and cope with injuries. For this purpose, in recent years, the research on injuries has increased to investigate their nature and incidence so that knowledge about injuries can increase and they can be prevented.

Different factors are involved in this process so sport psychology researchers have attempted to show that thoughts, emotions and personality traits may play a role in the incidence of injuries (Ciarrochi, Deane \& Anderson,2002). Today, in sport world, physical training is not the only key factor to achieve success and high performance and it seems that in addition to physical and tactical abilities and professional skills, personality traits are undoubtedly effective factors for sport performance. On the other hand, as athletes have to compete in stressful situations and as stress and anger are common in such situations, athletes will face excitement in such situations which are potentially stressful (Lazarus, 2000). The incidence of stress factors such as a reprimand from the coach; cheating by an opponent; an undesirable or bad coaching; undesirable environmental conditions; spectators reaction during the competition; desire to win at the expense of sport immorality; the experience of sport injury; cheating to win; and a criticism by the coach (Anshel, Williams \& Williams, 2000) necessitates effective coping factors to maintain athletes' mental health and to achieve sport success because the inability to cope with stress factors is harmful to athletes successful performance (Boyatzis, Goleman \& Rhee, 2000). As a result, one of the important personality traits which seems to affect athletes' performance in stressful situations such as sport situations and to prevent the effect of the inhibiting factors is mental skills and emotional intelligence (EI) (Schotte, Malouff, Thorsteinsson, Bhullar, \& Rooke, 2007). That is, if the athletes do not 
control stressful situations, not only will their performance decline but also they may be injured (Schotte, Malouff, Thorsteinsson, Bhullar \& Rooke, 2007).

Evaluating the personality of injured athletes, sport psychologists try to identify those common personality factors which may bear a relationship with the incidence of injury. Williams and Andersen (1999) suggested a theoretical pattern which described the relationship between stress and injury and was a basis of many researches in the present decade. In recent years, some models which approve the relationship between psychological factors and the incidence of injury have been designed; one of the most effective models is the stress-injury model of Williams and Andersen which divides the risk of psychological factors into three groups: personality characteristics, history of stressors and coping resources. Other models which emphasize the risk of special injury factors included the model of "the effect of psychological factors on sport injury" with three main psychological categories: history of stressors, coping resources and emotional state; "the experimental model of injury risk factors" (Ivarsson \& Johnson, 2010), and the model emphasizes on personality factors (Ivarsson \& Johnson, 2010). Also, situational factors and personality characteristics were determined as the determining factors of injury. Athletes who have a tendency towards threatening situations (high emotional behavior) or a history of stressful life (big life events and daily hassles) and weak coping resources (lack of social support) may have more negative stressful reactions and consequently may be more prone to injury.

Individuals with high stress will face higher perceptual limitations and competitive anxiety. Increased perceptual limitation is dangerous when the athletes face stressful situations (Andersen \& Williams, 1999). Reaction to stress is different from person to person and it is not predictable; the reaction is more dependent on somatic sensitivity and emotional intelligence rather than the intensity of the motive (Golman, 1995). Individuals need certain abilities to predict the events and face them properly so they are not personally or socially harmed or they can minimize their undesirable effects; one of these important abilities in this decade is emotional intelligence (Golman, 1995). Emotional intelligence is one of personality variables manifested in different forms in modern psychology literature due to different implications. Sport emotional intelligence not only in Iran but in other countries is known as a new approach to manage athletes' emotions and to amend their performance. The effect of emotions on athletic performance was approved by most researchers, coaches, sport managers and athletes before, during or after the competition; most athletes attribute their win or loss to emotional factors (Lazarus, 2000). In fact, excitement and coping styles is a part of personality which affects performance. However, due to the complexity of emotional states, most athletes are unaware of their strengths and weaknesses. The ability to perceive, infer and utilize emotional skills is different from person to person and this collection of awareness comprises emotional intelligence which plays a vital role in performance (Mayer, 1999). High emotional intelligence shows that how the individuals use their emotions desirably in different situations and manifest those emotional states which are necessary and proper in a certain situation; that is, if that situation needs a high motivation, emotional intelligence can increase athletes' motivation and on the other hand if a situation needs emotional relaxation, it can relax the athletes. Otherwise, if athletes have low emotional intelligence, they will show nonconformist behaviors such as non-commitment to exercise, little attempt and irresistance to failure while if they perceive, identify, regulate and show emotions more, they will perform better. Sport psychological researchers (Golman, 1998; Lane \& Lowther, 2005) concluded that the more ability athletes have to perceive, identify, regulate and show emotions, the more efficient they will be. Also, coaches can create an efficient sport environment through an improvement in emotional intelligence skill in athletes. John Mayer has defined emotional intelligence as "The ability to perceive emotion, integrate emotion to facilitate thought, understand emotions and to regulate emotions to promote personal growth" (Mayer, 1999). Emotional intelligence is to use emotions intelligently so individuals consciously use their emotions and enhance their thoughts and behaviors in the direction of their goals so that they can reach fantastic results (Halloran, 2008). Emotional intelligence provides the opportunity to think creatively and to utilize emotions, feelings and problems (Cherniss, 2000). John Mayer and Peter Salovey stated that emotional intelligence is "the ability to monitor one's own and others' feelings, to discriminate among them, and to use this information to guide one's thinking and action." Therefore, we investigated whether personality characteristics such as emotional intelligence had an effect on the amount of injury.

Wrestling is one of the oldest sports in the world and its history goes back to Olympics in Ancient Greece in 776 B.C. It is one of the most popular sports in the world. In America, more than 250000 male high school students participated in official wrestling matches during 2005-2006 which has made wrestling the 6th popular sport in the USA high schools. Wrestling bears many injuries; it is the sport with the second highest frequency of injuries following football. The main goal in wrestling is to gain and maintain a superior position so grappling and throws are common in wrestling (Kordi, Akbarnejad, Wallace, 2008). In addition, there are many dangerous and catastrophic injuries in wrestling and even in some cases neck and head injuries resulted in death or paralysis of the injured athlete (Ivarsson \& Johnson, 2010). Therefore, the researchers selected wrestling to study the role of emotional intelligence to create a variety of injury and suggesting new psychological for prevention of damage in the wrestling and other athletics.

\section{Method}

This research was correlational and descriptive. It aimed to evaluate the effect of emotional intelligence as a predictor variable on sport injuries as criterion variable.

\subsection{Participants}

Population of this study was all wrestlers who participate in Country Championships including 6 teams. Wrestlers $(n=90)$ with the mean age $19.40 \pm 5.5$ years, who had been invited to Iranian national team in 2012 , participated in the study. Before the survey, all of the athletics gave their informed consent for their participation in the study. Iran wrestling federation authorities and the institutional review board approved the research. 
Sports injury report was used to evaluate and describe the sport injuries and the athletes were interviewed (considering their medical records) to collect the necessary data.

Sport injury report: this form consists of different parts such as bone injuries, joint injuries, etc. in upper and lower extremities. The data of this form is represented as frequency which evaluates the total number of sport injuries. This form was designed in a research by Rezaie (2005) and the validity was reported as 0.78 .

Emotional Intelligence Scale: to measure emotional intelligence, the emotional intelligence scale by Schutte et al. (1998) was used. This scale consists of 33 questions based on the model of Salovey and Meyer (1997). Items of the test relate to the three aspects of EI: (1) regulation of emotion (2) utilization of emotion (3) evaluation of emotion based on 5-point Likert scale from 1 (strongly disagree) to 5 (strongly agree). Schutte et al. reported the reliability coefficient of this test as 0.78 for a sample of 28 university students with a 2 -week interval. Austin, Saklofske, Hang and McKenna (2004) reported the internal consistency of the items of this test from 0.84 to 0.90 through Cronbach' alpha coefficient. The validity of this test was determined through the measurement of its correlation with related constructs and it was reported as sufficient (Austin et al., 2004; Schutte et al., 1998). Besharat (2005) in the Persian version of this test reported Cronbach's alpha correlation coefficients of scores for 42 subjects of the above sample as 0.83 with a 2 -week interval which showed a satisfactory reliability of the test.

\subsection{Statistical Analysis}

Pearson correlation coefficient was used to find the relationship among the variables at significance level of 0.05 . For this purpose, linear regression was also used.

\section{Results}

The findings showed that the wrestlers suffered from an average of 12 injuries last year. Their mean score in 'regulation of emotion' subscale was 32.5, in 'utilization of emotion' was 28 , in 'evaluation of emotion' was 30 and in 'emotional intelligence’ was 90.5 generally (Table 1).

Table 1. descriptive statistics of the variables

\begin{tabular}{|l|l|l|l|l|l|}
\hline & Sample & Min. & Max. & Mean & SD \\
\hline Number of sport injuries & 90 & 10 & 35 & 11.73 & 8.99 \\
\hline Ability to regulate emotion & 90 & 18 & 47 & 32.51 & 7.58 \\
\hline Ability to utilize emotion & 90 & 13 & 37 & 28.11 & 5.76 \\
\hline Ability to evaluate emotion & 90 & 15 & 38 & 29.86 & 5.50 \\
\hline $\begin{array}{l}\text { Ability to generally regulate } \\
\text { emotion }\end{array}$ & 90 & 62 & 120 & 90.50 & 16.53 \\
\hline
\end{tabular}

Is there a relationship between the number of injuries and the ability to regulate emotion? The results showed a significant relationship in the negative direction between the number of sport injuries in wrestlers and their ability to regulate their emotion $(r=-0.309)$ at $95 \%$ significance $(P=0.016)$. Figure 1 shows that as the ability to regulate emotion decreases, the number of sport injuries increases.

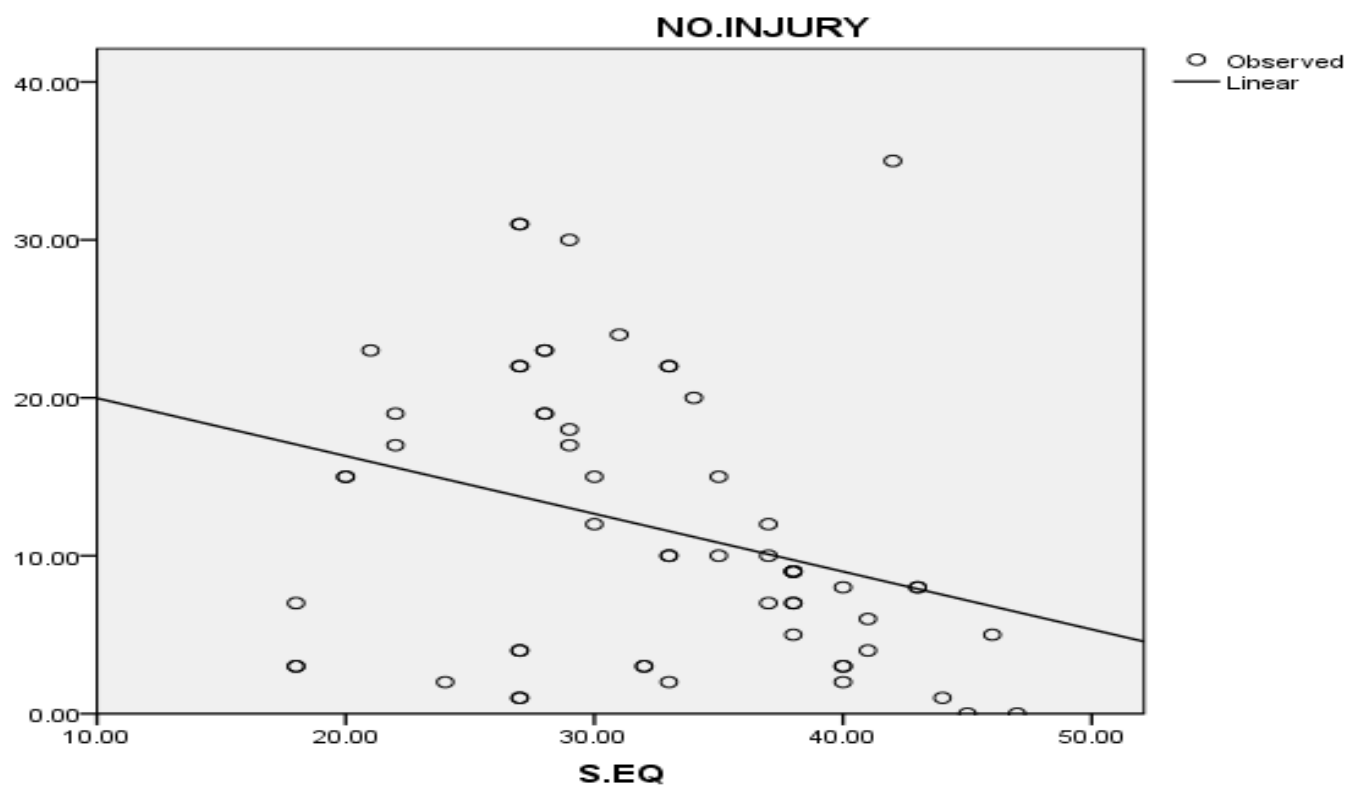

Figure 1. linear regression of the number of injuries and the ability to regulate emotion

there a relationship between the number of injuries and the ability to utilize emotion? The results showed a significant relationship in the negative direction between the number of sport injuries in wrestlers and their ability to utilize their emotion $(\mathrm{r}=-0.313)$ at $95 \%$ significance $(\mathrm{P}=0.015)$. Figure 2 shows that as the ability to utilize emotion decreases, the number of sport injuries increases. 


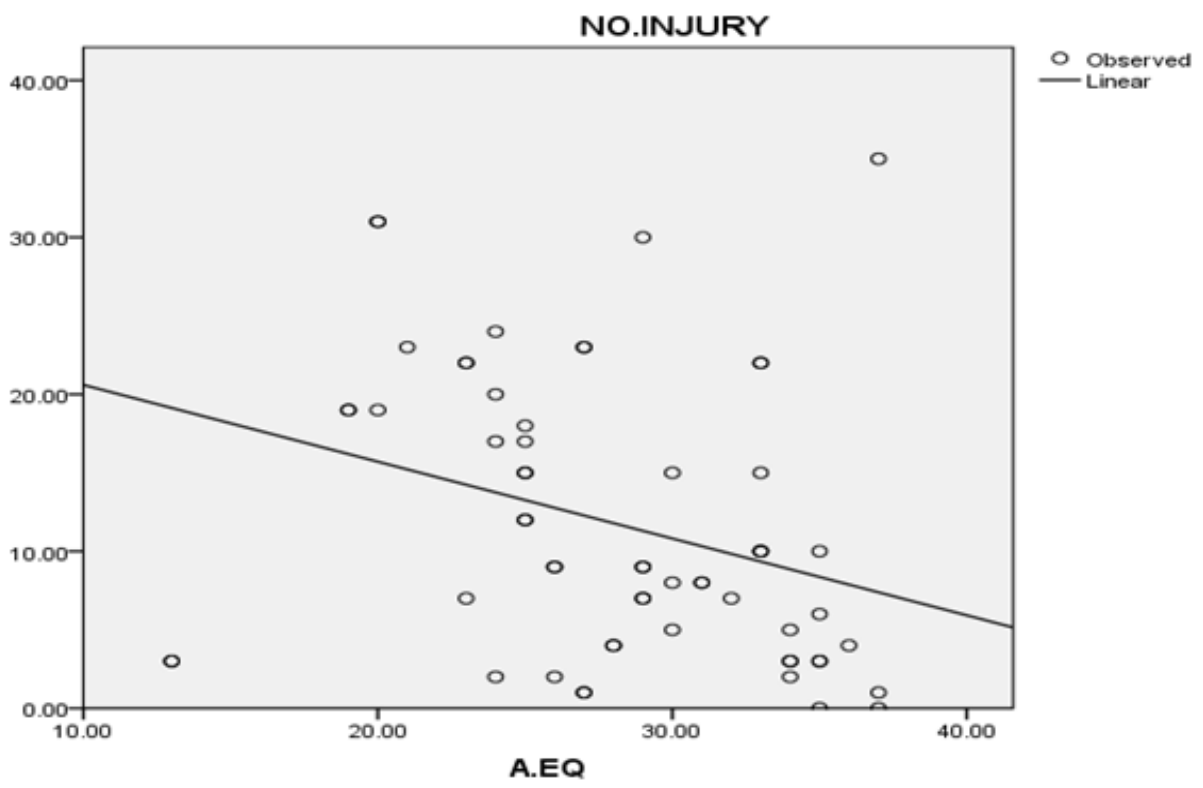

Figure 2. linear regression of the number of injuries and the ability to utilize emotion



Figure 3. linear regression of the number of injuries and the ability to evaluate emotion Is there a relationship between the number of injuries and the ability to regulate emotion generally? The results showed a significant relationship in the negative direction between the number of sport injuries in wrestlers and their ability to regulate their emotion generally $(r=-0.445)$ at $99 \%$ significance $(P=0.000)$. Figure 4 shows that as the ability to generally regulate emotion decreases, the number of sport injuries increases.

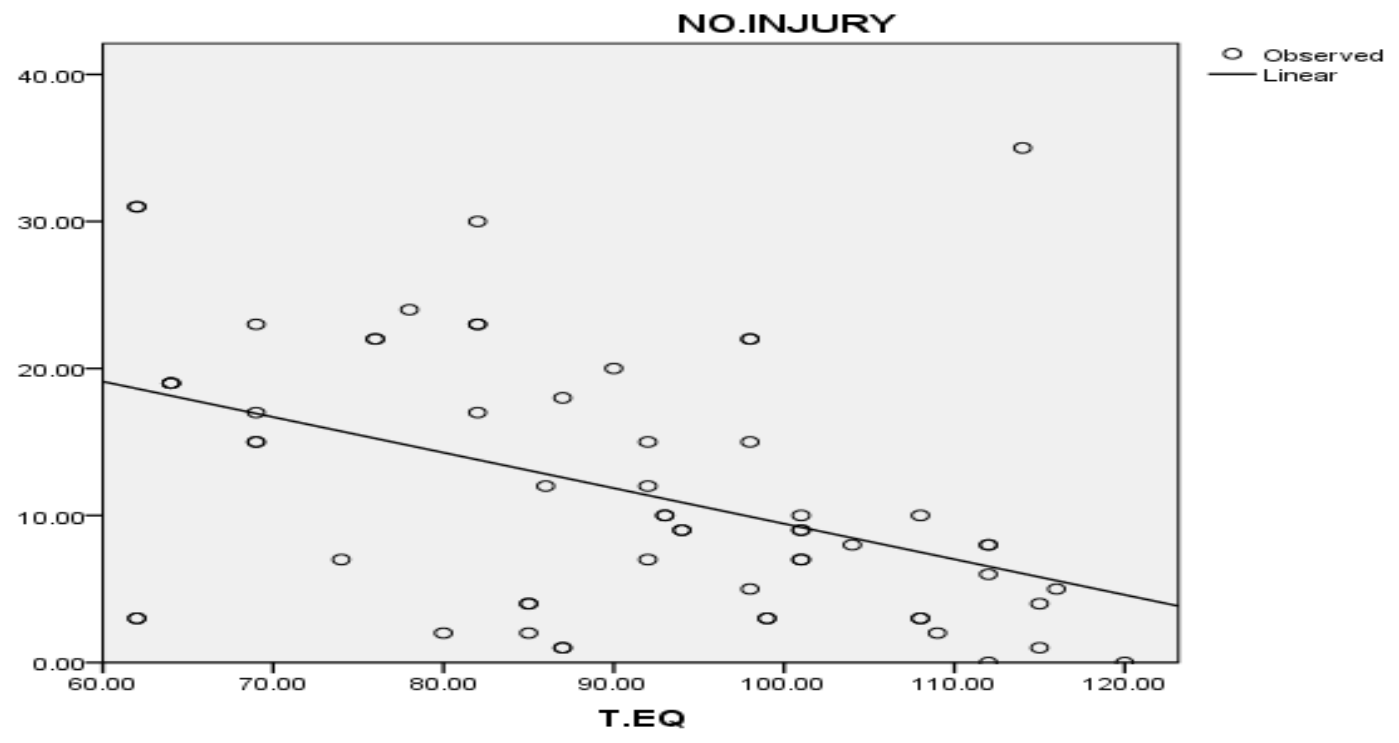

Figure 4. linear regression of the number of injuries and the ability to generally regulate emotion 
The regression model of the research was as follows:

Table 2. Regression of predictor variable (EI scores) on criterion variable (number of sport injuries)

\begin{tabular}{|c|c|c|c|c|c|}
\hline Model & $\mathrm{R}$ & $\mathrm{R}^{2}$ & Adjusted & $\mathrm{F}$ & Sig \\
\hline 1 & 0.582 & 0.339 & 328 & 29.778 & 0.00 \\
\hline
\end{tabular}

Is there a linear relationship between any of predictor variables and criterion variable? To answer this question, ANOVA analysis of variance was used. The above table showed a linear relationship between one of EI subscales (the ability to evaluate emotion) and the criterion variable $\left(\mathrm{F}=29.778, \mathrm{Sig}=0.00, \mathrm{R}^{2}=0.339\right)$.

\section{Discussion}

Generally, the results of this research showed a significant relationship in the negative direction between EI and the probability of injury in wrestlers, that is, as the ability to control EI increases, the probability of injury decreases and vice versa. But it is to be discussed whether EI as one of the psychological factors has an effect on injury or injury has an effect on EI; therefore, the results of this research will be compared with the results of other researches as follows. Also, it should be mentioned that the relationship between psychological factors and injury may be mutual, that is, both factors may have an effect on each other. But, the amount of this effect may be different and it may be dependent on the type of injury and psychological characteristic (Boyatzis, Goleman, \& Rhee, 2000).

Some researchers absolutely relate personality characteristics to athletes' injury. Generally, research on personality in sport and exercise is negotiable. There are two viewpoints in this regard; some researchers consider a significant role for personality in injury and the other group believes in an insignificant role. Some other researchers suggest that the right viewpoint is in the middle of the above viewpoints (Gould, Petlichkoff, Prentice, \& Tedeschi, 2000).

A contrary research is Anderson (Lees \& Barnard, 1999) which investigated talent identification indexes in karate. The results showed no significant relationship between mental preparedness factors and success in karate players. On the other hand, most researches showed that motivation (to sufficient extent), self-confidence, emotion focus and control and intelligence are essential factors in success in all sport fields especially wrestling. As a result, in developed countries, psychological preparedness is an important part of talent identification tests to select talented individuals for specific fields (Bar-on, 1999).

The viewpoint of wrestling coaches and professionals show a high relationship between psychological preparedness indexes and success in wrestlers, so that they believe that motivation, self-confidence, focus and emotion control have a great effect on wrestlers success. Although coaches strongly believe in psychological issues of athletes, this issue is not considered in sport teams and most club teams and even national teams do not have psychological coaches and coaches do not receive sufficient education. Educational courses also are limited to physiology and training and psychological courses are limited as well (Lees \& Barnard, 1999).

The present results are in line with the previous researches (Bar-on, 1999; Cogan \& Brown, 1999; Lafreniere, Menna, \& Cramer, 2009; Slanger \& Rudestam, 1997); all these researches showed a significant relationship between psychological factors and sport performance and mistake (injury).

As in researches on psychological factors especially stressors, personality and emotional intelligence have been received less attention, Andersen and Williams (1999) proposed that determined personality behaviors such as stubbornness can predict some aspects of sport situations of the athletes such as lower threatening and aggressiveness which finally result in lower stress responses and lower injury risks. Other behaviors such as competitive anxiety provoke athletes to show more drastic stress responses in competitive situations and as a result injury risk may increase (Andersen \& Williams, 1999). Researches show different findings about personality and sport injury; some showed a relationship between self-concept, abstinence, state anxiety and injury (Junge, 2000) while no academic research has been carried out on emotional intelligence and sport injury. Therefore, the authors tended to evaluate the relationship between emotional intelligence and injury.

If athletes are able to manage their emotion properly and utilize it properly and in fact if they have a high emotional intelligence, they will prevent the effects of stressors and disturbing factors. In fact, emotional intelligence is one of the skills to cope with stress; on the contrary, if athletes have lower ability to manage their emotion, stress and muscle tension will increase and disrupt neuromuscular interaction and finally will result in injury. This finding is in line with Andersen and Williams' model (Andersen \& Williams, 1999).

Regression model in this research showed that among emotional intelligence subscales, only 'evaluation of emotion' subscale could predict the probability of injury in wrestlers which shows that emotional intelligence can be one of the predictors of injury in wrestlers. One of the reasons why other subscales could not predict injury was the low number of subjects.

In spite of facilities and proper situations, risk of injury may still exist and injury may create catastrophic psychological consequences; therefore, it is suggested that stress management methods are used, psychological factors of athletes are controlled, educational courses to promote emotional intelligence are held so that athletes performance and efficiency can improve and injuries can be predicted and decrease. 
The results showed that if wrestlers have a high ability to regulate their emotion, they will suffer from lower injuries. The significant relationship between EI subscale and the number of injury in wrestlers shows that athletes with lower ability to regulate their EI may impose lower control on their muscle tension and neuromuscular interaction. Consequently they will experience risky situations and more injuries. They will stay away from sport arenas and pay more and more for their treatment. Therefore, coaches and officials are recommended to recognize these athletes and try to improve their emotional intelligence with Education classes and Workshops, so that they can decrease the probability of sport injuries.

\section{Conclusions}

The current study found a number of significant psychological predictors that increase the injury risk among wrestlers. One implication for both players and coaches is to be aware of the identified variables and their impact on injury risk in order to prevent sport injuries. Further research could investigate how emotional intelligence affects injury risk among wrestlers in a larger sample and at more highly competitive levels as well as studying both male and female wrestlers. It would also be interesting if further research, with knowledge from previous studies, could design an intervention based on one experimental and one control group, to investigate the possibility of using mental skills training to prevent sports injuries.

\section{References}

Andersen, B, m and Williams, M, J (1999). "Athletic injury, psychosocial factors and perceptual changes during stress". Journal of Sports Sciences, 17, 9.

Anshel, M. H, Williams, L. R. T, and Williams, S. M. (2000). "Coping style following acute stress in competitive sport". The Journal of Social Psychology, 140, 751- 773.

Bar-on, R. (1999). The Emotional Quotient Inventory (EQ-I).A Measure of Emotional Intelligence. Toronto, Canada: Multi- Health system.

Boyatzis, R., Goleman, D., and Rhee, K. (2000). Clustering competence in emotional intelligence: Insights from the emotional competence inventory (ECI). In R. Bar-On and J.D.A. Parker (Eds.), Handbook of emotional intelligence. San Francisco: Jossey-Bass.

Cherniss, C. (2000) "Emotional intelligence what is and why it Matters". Annual Meeting of society for industrial and organizational Psychology new.

Ciarrochi, J, Deane, F. P. \& Anderson, S. (2002). Emotional intelligence moderates the relationship".

Cogan, N \& Brown, R. (1999). "Metamotivational dominance, states and injuries in risk and safe sports, personality and individual differences". 27, pp: 503-518.

Golman, D. (1995). "Emotional Intelligence: Why It Can Matter More Than IQ". New York: Bantam Books.

Golman ,D . (1998). "What make a leader?". Harvard Business Review.

Gould. D., L. Petlichkoff, B. Prentice, F. Tedeschi. (2000)." Psychology of sport injuries". Gatorade sports science institute, RT \# 40. 11.

Halloran L. (2008). "Wrestling Injuries". Orthopedic Nursing; 27(3):189-194.

Lazarus, R.S. (2000). "How emotions influence performance in competitive sports". The Sport Psychologist.

Ivarsson, A and Johnson, U (2010). "Psychological factors as predictors of injuries among senior soccer players". A prospective study. CJournal of Sports Science and Medicine (2010) 9, 347-352.

Junge. A. (2000). "The Influence of Psychological Factor on Sports Injuries". American Journal of Sports medicine. Volume28, suppl 5, p.p 10-15.

Kordi R, Akbarnejad A, Wallace AW (2008)."Catastrophic Injuries in the Olympic styles of wrestling in Iran". Br J Sports Med. Jul 4.

Lafreniere, DK Menna, R. Cramer, M.K. \& Out, W.J. (2009). "Metamotivational and temperament al predictors of adolexcent risk taking". 14th international reversal theory Conference July 2009: New Orlean, Louisiana, USA.

Lane, A .M, and Lowther, J (2005). "Relationship between emotional intelligence and Psychological skills among athletes (PARTV: psychology)". Journal of sports sciences, (November, 2005).

Lane, A .Thelwell, R. Lowther, J, and Davonport, T, J (2009). "Emotional intelligence and Psychological skills use among athletes". Social behavior and personality: an international Journal volume 37, number 2, p.p195 - 201(7).

Lees, A. and Barnard, D. (1999). Highly effective head teachers: an analysis of a sample of diagnostic data from the Leadership Programmers for Serving Head teachers. Report prepared for Hay/McBer.

Mayer, J. D. (1999). "Emotional intelligence: popular or scientific psychology" A. P. R. Monitor, 30, P:8.

Mayer,J.D.\& Salovey, P.(1997) What is emotional intelligence? In P. salovey \& D.J Sluyter(Eds), Emotional 
Development and Emotional intelligence: Emotional Implication: 3-31. New York : Basic Books.

National Federation of State High School Associations. (2007). NFHS participation figures search. Available at: http://www.nfhs.org/custom/ participation figures/default.aspx. Accessed August.

National Federation of State High School Associations. 2005-06 High School Athletics Participation Survey. Available at: http://nfhs.org/core/contentmanager/uploads/2005_06NFHSparticipationsurvey .pdf. Accessed August 2007.

Schotte, N.S., Malouff, J.M., Thorsteinsson, E.B., Bhullar, N., \&Rooke, S.E. (2007). a Meta-analytic Investigation of Relation between Emotional Intelligence and Health. Personality and Individual Differences 42, 921-933.

Slanger, E. \&rudestam, KE.(1997). "Motivation and disinhibition in high risk sports: Sensation seeking and self efficacy". Journal of Research in Personality, 31, PP: 355-374.

Weinberg, R., and D. Gould. (2003). "Foundations of sport and exercise psychology". Handbook of Sport Psychology. Champaign. IL: Human Kinetics. 3, 428-442.

Williams, J, M and Andersen, B, M (1998). "Psychosocial Antecedents of Sport Injury": Review and Critique of the Stress and Injury Model. JOURNAL OF APPLIED SPORT PSYCHOLOGY 10, 5-25. 